\title{
Reproducibility of echocardiographic estimates of left ventricular dimensions
}

\author{
M. A. STEFADOUROS AND M. I. CANEDO \\ With the technical assistance of Mrs. Beryl Wilson \\ From the Division of Cardiology, Department of Medicine, Medical College of Georgia, Augusta, \\ Georgia 30902, U.S.A.
}

Although echocardiography is ideally suited for repetitive use on a patient for evaluation of left ventricular function, the value of this application is minimised by the uncertainty as to whether changes in left ventricular dimensions observed on a patient at different times or by different observers are real or result from the ultrasonic beam penetrating the left ventricle at different angles. Accordingly, an instrument was designed and constructed in our laboratory to improve the reproducibility of echocardiographic measurements of left ventricular dimensions. The instrument represents an orthogonal reference frame by means of which the spatial orientation of the ultrasonic beam relative to the chest is determined and reproduced in subsequent studies, while the point of entrance of the beam is marked on the chest wall.

Using this instrument, left ventricular echograms were initially recorded on a group (I) of 23 subjects with or without heart disease and the study was repeated 8 hours to 49 (mean 7) days later by the same observer and also, in 16 cases, by an independent observer. The average values from 2 to 6 (mean 4) heart cycles were used for the left ventricular end-diastolic dimension (Dd), end-systolic (Ds) dimension, and their difference $(\Delta D)$. Differences in all three variables between studies were random and statistically insignificant, never exceeding $3.5 \mathrm{~mm}$ for $D d$ or $D s$, and $4 \mathrm{~mm}$ for $\Delta D$.

For comparison, left ventricular internal dimensions were also obtained in a separate group (II) of 14 subjects by the standard method of using the mitral valve as an internal landmark, without the benefit of this instrument. All 14 subjects had the initial study repeated within 8 hours to 11 (mean 3.8) days later by the same and also by an independent observer. Though in the group as a whole there was no significant difference in left ventricular dimensions between studies, individual variations reached $11 \mathrm{~mm}$ for $D d, 9 \mathrm{~mm}$ for $D s$, and $9 \mathrm{~mm}$ for $\Delta D$, and the degree of scatter was significantly larger than in group $I$.

This initial experience indicates that the use of this instrument improves the reproducibility and enhances the reliability of estimates of echocardiographic left ventricular dimensions and function on a patient examined at different times by the same or independent observers.

Identification of echoes originating from the endocardium of the left ventricular posterior wall and from that of the left side of the interventricular septum permits measurement of the left ventricular internal dimension throughout the cardiac cycle. Several investigators have previously validated the use of this single dimension for the noninvasive determination of the volume (Popp et al., 1969; Feigenbaum et al., 1970; Fortuin et al., 1971; Pombo et al., 1971), output (Popp and Harrison, 1970; Pombo et al., 1971), and performance (Paraskos et al., 1971; Pombo et al., 1971; Cooper et al., 1972; Fortuin et al., 1972) of the left ventricle. Since it is Received for publication 28 May 1976 noninvasive, echocardiography is ideally suited for repetitive use to establish changes in left ventricular size and performance as a consequence of either the natural evolution of the disease or the treatment. This application, however, is hampered by the uncertainty as to whether the changes in left ventricular dimension and function observed on a patient in serial studies carried out by the same or a different observer are real or artificial, caused by sampling from different sites of the left ventricular walls. It has been stated that the requirement of recording continuous echoes from the endocardium of the left ventricular posterior wall and of the left side of the interventricular septum, with the ultra- 
sonic transducer applied on the third or fourth left intercostal space, represents adequate constraint limiting the area of the left ventricle from which measurement of its standardised internal dimension can be made (Feigenbaum and Chang, 1972). Our experience and that of Popp et al. (1975), however, is that this requirement does not always ensure that the same left ventricular dimension will be recorded. Fig. 1 shows 9 left ventricular echograms obtained by one observer, from a patient in the supine position during one study period. It was possible to record echograms from the third, fourth, and fifth left interspaces parasternally. From each interspace three echograms were obtained by varying the angle of the transducer. All 9 echograms showed echoes from the endocardium of both the left side of the interventricular septum and the posterior left ventricular wall, and presented evidence of the mitral valve apparatus within the space of the left ventricle. There were distinct differences in the values obtained from different interspaces or from the same interspace at different angles, reaching $19 \mathrm{~mm}$ and $13 \mathrm{~mm}$ for the end-diastolic and the end-systolic dimension, respectively.

This report describes the results of the use of an instrument designed to improve the reproducibility of echocardiographic determination of left ventricular dimensions.

\section{Subjects and methods}

Using the instrument described below, echocardiographic studies for determination of the internal dimension of the left ventricle were conducted on a group (I) of 23 subjects (study A) and repeated 8 hours to 49 (mean 7) days later by the same observer (study B), and also in 16 cases by an independent observer (study C). Eight of these subjects had no overt heart disease. The remaining 15 subjects were patients with heart disease selected on the basis of two requirements: (1) that in all studies they were in normal sinus rhythm or sinus tachycardia and (2) that no cardiac treatment was started, discontinued, or modified in the interval between studies. Data concerning age, sex, and diagnosis of the study population are listed in Table 1 .

In a separate control group (II) of 14 subjects, left ventricular echograms were obtained in the supine position using the standard method with the mitral valve as an internal landmark (study A) and repeated 8 hours to 11 (mean 3.8) days later by the same (study B) and also by a separate observer (study C). In none of these studies was the instrument used or the scanning method employed. Seven of these subjects had no overt heart disease. The remaining 7 were patients with heart disease

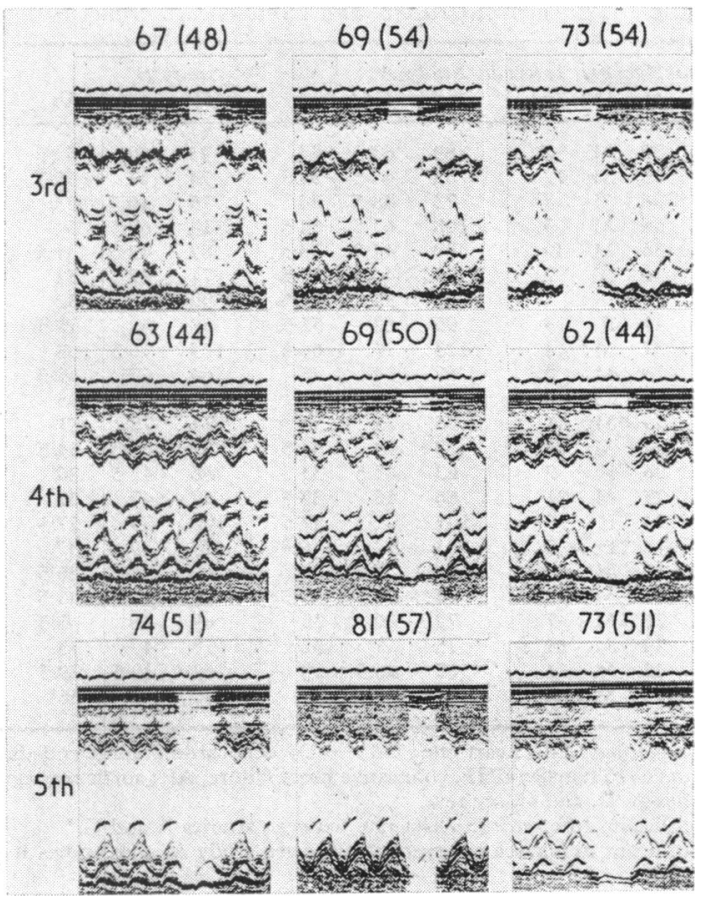

Fig. 1 Left ventricular echograms obtained by one observer during one study period on a patient with aortic regurgitation, in the supine position. Three echograms were obtained from each of the third (upper), fourth (middle), and fifth (lower) left interspaces parasternally, by changing the direction of the ultrasound transducer. The numbers at the top of each picture represent the end-diastolic and, within parentheses, the end-systolic left ventricular dimensions. The tissue depth scale is the same in all pictures and has been retouched for clarity in the left picture of the upper row. Though the endocardium of the left side of the septum and of the posterior left ventricular wall is clearly delineated and parts of the mitral valve apparatus are represented in most of the pictures, differences in heart dimensions, even when obtained from one interspace, are marked.

selected on the basis of the same two requirements applied in the group I, concerning heart rate and cardiac treatment. Data on age, sex, and diagnosis of group II are listed in Table 2.

To avoid the effect of heart rate on the heart size, comparison of left ventricular dimensions in both groups between studies showing a difference in heart rate in excess of 15 per cent were omitted. Five subjects were excluded because a good quality left ventricular echogram was unobtainable in the first study. All studies on each subject were conducted at approximately the same time of the day.

A Smith Kline Ekoline 20 echograph $^{1}$ was used 
Table 1 Echocardiographic and clinical data from 23 subjects of group I

\begin{tabular}{|c|c|c|c|c|c|c|c|c|c|c|c|c|c|}
\hline $\begin{array}{l}\text { Case } \\
\text { No. }\end{array}$ & $\begin{array}{l}\text { Age } \\
\text { and }\end{array}$ & $\begin{array}{l}(y) \\
\text { Sex }\end{array}$ & $\begin{array}{l}\text { Interval } \\
\text { (d) }\end{array}$ & $\begin{array}{l}\text { Study } \\
\text { HR }\end{array}$ & $\begin{array}{l}A \\
D d\end{array}$ & Ds & $\begin{array}{l}\text { Study } \\
\text { HR }\end{array}$ & $\begin{array}{l}B \\
D d\end{array}$ & Ds & $\begin{array}{l}\text { Study } \\
\text { HR }\end{array}$ & $\begin{array}{l}C \\
D d\end{array}$ & Ds & Diagnosis \\
\hline 1 & 32 & $\mathbf{M}$ & 2 & 89 & $63 \cdot 5$ & 54 & 93 & 60 & 52.5 & & \multirow{7}{*}{\multicolumn{2}{|c|}{$\begin{array}{l}\text { Not done } \\
\text { Not done } \\
\text { Not done } \\
\text { Not done } \\
\text { Not done } \\
\text { Not done } \\
\text { Not done }\end{array}$}} & Aortic valve prosthesis, cardiomyopathy \\
\hline 2 & 25 & $\mathbf{M}$ & 12 & 82 & $48 \cdot 5$ & 34 & 74 & 47 & $35 \cdot 5$ & & & & No heart disease \\
\hline 3 & 26 & $\mathbf{M}$ & 5 & 73 & $48 \cdot 5$ & 34 & 76 & 46.5 & 33 & & & & No heart disease \\
\hline 4 & 68 & $\mathbf{M}$ & 3 & 108 & $65 \cdot 5$ & $54 \cdot 5$ & 114 & $65 \cdot 5$ & 54 & & & & CHF, myocardial infarction \\
\hline 5 & 34 & $\mathbf{M}$ & 49 & 89 & $44 \cdot 5$ & $33 \cdot 5$ & 82 & $42 \cdot 5$ & $31 \cdot 5$ & & & & No heart disease \\
\hline 6 & 30 & $\mathbf{M}$ & 2 & 73 & 44 & $29 \cdot 5$ & 77 & 42.5 & 32 & & & & Hypertension, AR \\
\hline 7 & 35 & $\mathbf{F}$ & 1 & 95 & $39 \cdot 5$ & $31 \cdot 5$ & 90 & 38 & 32 & & & & Atrial septal defect \\
\hline 8 & 47 & $\mathbf{F}$ & 3 & 90 & 62 & $55 \cdot 5$ & 83 & 62 & $55 \cdot 5$ & 78 & 62.5 & $57 \cdot 5$ & CHF \\
\hline 9 & 37 & $\mathbf{M}^{\star}$ & 4 & 123 & 77 & $68 \cdot 5$ & 107 & $76 \cdot 5$ & 68 & 100 & 77 & $69 \cdot 5$ & Coronary artery disease, $\mathrm{MR}$ \\
\hline 10 & 19 & $\mathbf{M}$ & 2 & 68 & 64 & 45 & 64 & 67 & $45 \cdot 5$ & 73 & 65 & 44 & \\
\hline 11 & 39 & $\mathbf{M}$ & 2 & 74 & $42 \cdot 5$ & 33 & 85 & 41 & 35 & 83 & $42 \cdot 5$ & $32 \cdot 5$ & Angina, hypertension \\
\hline 12 & 39 & $\mathbf{M}_{\dagger}$ & 1 & 96 & 75 & 50 & 75 & 75 & 51 & 77 & $74 \cdot 5$ & $49 \cdot 5$ & No heart disease \\
\hline 13 & 37 & $M^{\star}$ & 18 & 78 & 49 & $34 \cdot 5$ & 67 & $52 \cdot 5$ & $34 \cdot 5$ & 64 & 49 & $32 \cdot 5$ & $\mathrm{AS}, \mathrm{AR}$, angina, $\mathrm{CHF}$ \\
\hline 14 & 26 & $\mathbf{F}$ & 2 & 63 & 43.5 & 31 & 66 & 43.5 & 30 & 68 & $46 \cdot 5$ & 31 & Mitral valve prosthesis, $\mathbf{A R}$ \\
\hline 15 & 25 & $\mathbf{M}$ & 21 & 66 & 45 & $32 \cdot 5$ & 67 & 47 & 31 & 65 & 46 & 31 & No heart disease \\
\hline 16 & 24 & $\mathbf{F}$ & 3 & 101 & 41.5 & $27 \cdot 5$ & 100 & 39 & $27 \cdot 5$ & 102 & 39.5 & $24 \cdot 5$ & Prolapsed mitral valve, hyperthyroidism \\
\hline 17 & 18 & $\mathbf{F}$ & 5 & 73 & $52 \cdot 5$ & 36.5 & 75 & 49 & 37 & 76 & 52 & $37 \cdot 5$ & $\mathrm{MR}, \mathrm{AR}$ \\
\hline 18 & 11 & $\mathbf{M}$ & $1 / 3$ & 70 & $35 \cdot 5$ & 26 & 69 & 38 & $26 \cdot 5$ & 71 & 36.5 & $26 \cdot 5$ & No heart disease \\
\hline 19 & 35 & $\mathbf{M}$ & 3 & 86 & 61.5 & $39 \cdot 5$ & 82 & 65 & $41 \cdot 5$ & 81 & 63.5 & 40 & Sickle cell anaemia, $M R$ \\
\hline 20 & 26 & $\mathbf{M}$ & 7 & 72 & 50 & 35 & 69 & 48 & 33.5 & 69 & 47 & 33.5 & No heart disease \\
\hline 21 & 29 & $\mathbf{M}$ & 14 & 75 & 47 & 32 & 78 & 47 & 33 & 70 & $45 \cdot 5$ & 34 & No heart disease \\
\hline 22 & 22 & $\mathbf{M}$ & 1 & 65 & $46 \cdot 5$ & 29 & 63 & $49 \cdot 5$ & $29 \cdot 5$ & 63 & 46.5 & 28 & $\mathbf{A R}$ \\
\hline 23 & 39 & $\mathbf{M}$ & 2 & 68 & 52.5 & 38 & 70 & 53 & 36 & 67 & 53.5 & $38 \cdot 5$ & Hypertension \\
\hline
\end{tabular}

Abbreviations: HR, heart rate; Dd and Ds, echocardiographic end-diastolic and end-systolic left ventricular dimension (in mm), respectively M, male; F, female; CHF, congestive heart failure, AR: aortic regurgitation; MR, mitral regurgitation; AS, aortic stenosis. For explanation'of studies $A, B$, and $C$, see text.

$\star$ Significant difference in heart rate between studies $A$ and $C$

† Significant difference in heart rate between study $A$, and studies $B$ and $C$.

for recording the left ventricular echograms on Polaroid film or strip chart, during 'time-motion' presentation with the transducer ${ }^{2}$ held stationary on the chest; the M-mode sector scanning technique was not used. The vertical distance between the echoes from the endocardium of the left side of the interventricular septum and from that of the left ventricular posterior wall was measured at end-

'Smith Kline Instruments, Palo Alto, California.

2.25 MHz focusing transducer (model C-14). diastole (Dd) defined by the $\mathbf{R}$ wave of the electrocardiogram, and at end-systole (Ds), defined by the peak anterior motion of left ventricular posterior wall (Fig. 2). The average values for $\mathrm{Dd}$ and $\mathrm{Ds}$ from 2 to 6 (mean 4) cardiac cycles, rounded to the nearest $0.5 \mathrm{~mm}$, were used. Special care was taken to avoid bias during measurement of left ventricular dimensions on the echograms. Thus, at the completion of the project, all echograms, containing full identification data on the back, were mounted on

Table 2 Echocardiographic and clinical data from 14 subjects of group II

\begin{tabular}{|c|c|c|c|c|c|c|c|c|c|c|c|c|c|}
\hline $\begin{array}{l}\text { Case } \\
\text { No. }\end{array}$ & $\begin{array}{l}\text { Age } \\
\text { and }\end{array}$ & $\begin{array}{l}(y) \\
\operatorname{sex}\end{array}$ & $\begin{array}{l}\text { Interval } \\
\text { (d) }\end{array}$ & $\begin{array}{l}\text { Study } \\
\text { HR }\end{array}$ & $\stackrel{A}{D d}$ & $D s$ & $\begin{array}{l}\text { Study } \\
H R\end{array}$ & $\begin{array}{l}B \\
D d\end{array}$ & $D s$ & $\begin{array}{l}\text { Study } \\
\text { HR }\end{array}$ & $\begin{array}{l}C \\
D d\end{array}$ & $D s$ & Diagnosis \\
\hline $\begin{array}{r}1 \\
2 \\
3 \\
4 \\
5 \\
6 \\
7 \\
8 \\
9 \\
10 \\
11 \\
12 \\
13 \\
14\end{array}$ & $\begin{array}{l}44 \\
13 \\
26 \\
27 \\
32 \\
28 \\
20 \\
23 \\
36 \\
33 \\
23 \\
16 \\
26 \\
49\end{array}$ & $\begin{array}{l}\mathbf{M} \\
\mathbf{F} \\
\mathbf{M} \\
\mathbf{F}^{\star} \\
\mathbf{M}^{\star} \\
\mathbf{M} \\
\mathbf{M} \\
\mathbf{F} \\
\mathbf{M} \\
\mathbf{M} \\
\mathbf{M} \\
\mathbf{M} \\
\mathbf{M} \\
\mathbf{F}\end{array}$ & $\begin{array}{l}1 / 3 \\
3 \\
7 \\
1 / 3 \\
7 \\
11 \\
2 \\
1 \\
1 / 3 \\
7 \\
7 \\
3 \\
2 \\
2\end{array}$ & $\begin{array}{r}65 \\
80 \\
70 \\
85 \\
95 \\
55 \\
91 \\
79 \\
69 \\
61 \\
63 \\
76 \\
84 \\
113\end{array}$ & $\begin{array}{l}60 \\
45 \cdot 5 \\
45 \\
61 \cdot 5 \\
45 \cdot 5 \\
44 \cdot 5 \\
55 \\
50 \\
45 \\
49 \cdot 5 \\
42 \\
60 \\
55 \cdot 5 \\
46 \cdot 5\end{array}$ & $\begin{array}{l}40 \cdot 5 \\
28 \cdot 5 \\
33 \\
58 \cdot 5 \\
31 \cdot 5 \\
27 \cdot 5 \\
40 \\
35 \cdot 5 \\
28 \\
28 \\
31 \cdot 5 \\
41 \cdot 5 \\
34 \\
29 \cdot 5\end{array}$ & $\begin{array}{r}63 \\
83 \\
80 \\
102 \\
76 \\
60 \\
103 \\
87 \\
70 \\
57 \\
64 \\
66 \\
82 \\
124\end{array}$ & $\begin{array}{l}54 \\
42 \\
41 \\
63 \\
46 \\
45 \\
54 \cdot 5 \\
53 \\
55 \cdot 5 \\
51 \\
45 \\
64 \cdot 5 \\
51 \\
43 \cdot 5\end{array}$ & $\begin{array}{l}41 \\
28 \\
27 \\
57 \cdot 5 \\
34 \cdot 5 \\
28 \\
43 \\
37 \\
36 \cdot 5 \\
34 \\
27 \cdot 5 \\
41 \cdot 5 \\
37 \\
29 \cdot 5\end{array}$ & $\begin{array}{r}65 \\
73 \\
74 \\
96 \\
82 \\
60 \\
99 \\
90 \\
66 \\
60 \\
66 \\
66 \\
83 \\
119\end{array}$ & $\begin{array}{l}60 \\
49 \\
41 \cdot 5 \\
65 \\
48 \\
45 \\
51 \\
55 \\
56 \\
55 \\
45 \\
65 \cdot 5 \\
47 \cdot 5 \\
40\end{array}$ & $\begin{array}{l}41 \cdot 5 \\
26 \\
28 \cdot 5 \\
56 \cdot 5 \\
35 \\
26 \\
37 \cdot 5 \\
35 \cdot 5 \\
36 \\
37 \\
27 \\
44 \cdot 5 \\
31 \\
24 \cdot 5\end{array}$ & $\begin{array}{l}\text { Chronic renal failure, hypertension } \\
\text { No heart disease } \\
\text { No heart disease } \\
\text { Hypertension, CHF } \\
\text { No heart disease } \\
\text { Prolapsed mitral valve } \\
\text { No heart disease } \\
\text { Mitral regurgitation } \\
\text { No heart disease } \\
\text { No heart disease } \\
\text { No heart disease } \\
\text { Aortic regurgitation } \\
\text { Hyperthyroidism } \\
\text { Prolapsed mitral valve }\end{array}$ \\
\hline
\end{tabular}

Abbreviations: Same as in Table 1.

$\star$ Significant difference in heart rate between studies $A$ and $B$. 


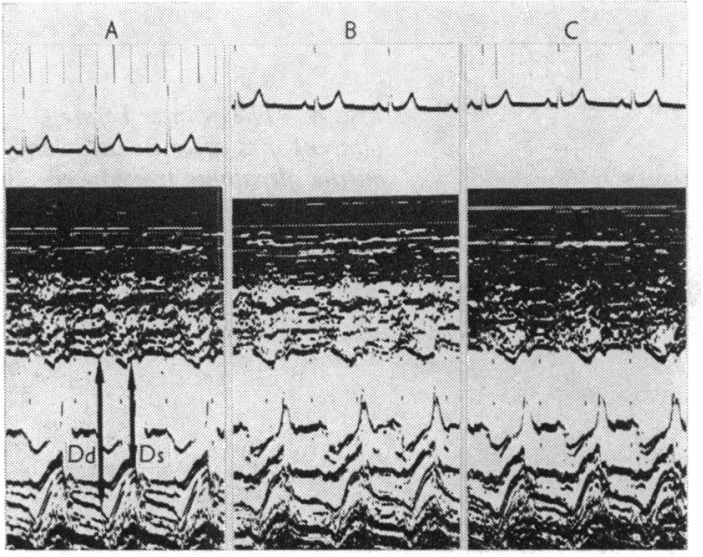

Fig. 2 Representative echograms of the left ventricle obtained on Case 18 (see Table 1) by the first observer $(A)$, and repeated 8 hours later by the same (B) and an independent observer $(C)$. All three echograms were obtained by use of the instrument.

Dd and Ds: end-diastolic and end-systolic left ventricular dimension, respectively.

non-transparent cards and randomly assigned to each of the two observers who independently carried out the measurements.

In each of the two groups, values for $\mathrm{Dd}, \mathrm{Ds}$, and $\Delta \mathrm{D}$ from studies $\mathrm{A}$ and $\mathrm{B}$ were compared with each other and also with those obtained from study C. Statistical analysis of the results was done separately for each group, using the Student's $t$ test for paired data. The level of statistical significance was set at $\mathrm{P}<0.05$.

The instrument used in the studies of group I
(Fig. 3) consists of a rectangular $(89 \times 193 \mathrm{~cm})$ hard wooden board that has receptacles for the attachment of four metal poles supporting a rectangular $(56 \times 69 \mathrm{~cm})$ transparent acrylic plate at a fixed height $(48 \mathrm{~cm})$ above the board. The surface of the plate is divided in centimetre squares so that any point on it can be identified by its co-ordinates on the $\mathrm{X}$-axis (right-left) and Y-axis (head-foot). The scale of these axes is marked along the corresponding edges of the plate. A special telescopic pointer (Fig. 4), constructed in our labroatory, can be firmly attached to the back of the ultrasonic transducer and manually expanded along an imaginary extrapolation of the central longitudinal axis of the ultrasonic beam.

The board, covered by a sheet, is placed on the examining bed ${ }^{1}$ whose surface is hard enough to prevent sagging. The subject to be examined is placed on the board with the long axis of the body parallel to that of the board, as checked by visual observation, and the head supported by a small pillow. The metal poles are screwed into place, the plate is placed on top of them, and the system is ready for use.

In the first study the transducer, with the pointer attached to it, is applied on the sternal end of the 4th or 5th left intercostal space with firm and steady pressure, and all necessary adjustments in the direction of the transducer or the gain and depth compensation controls are made until a technically satisfactory left ventricular echogram appears on the oscilloscopic screen. When the picture is about to be taken, the examined person is instructed to remain still and breathe shallowly, and an assistant manually

'WALK-OFF' Physical Therapy Treatment Table, Laberne MFG, Columbia, S.C.

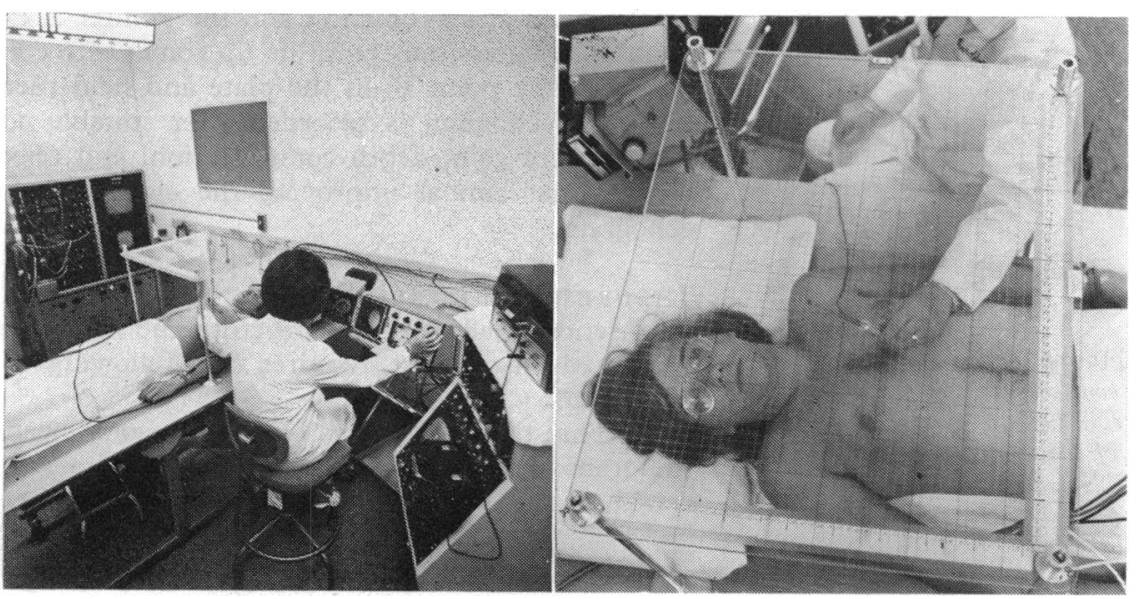

Fig. 3 The instrument in use as seen from a distance (left); $a$ close-up view from above (right). The echogram is about to be taken. The tip of the pointer is kept in contact with the plate by an assistant (not shown). 


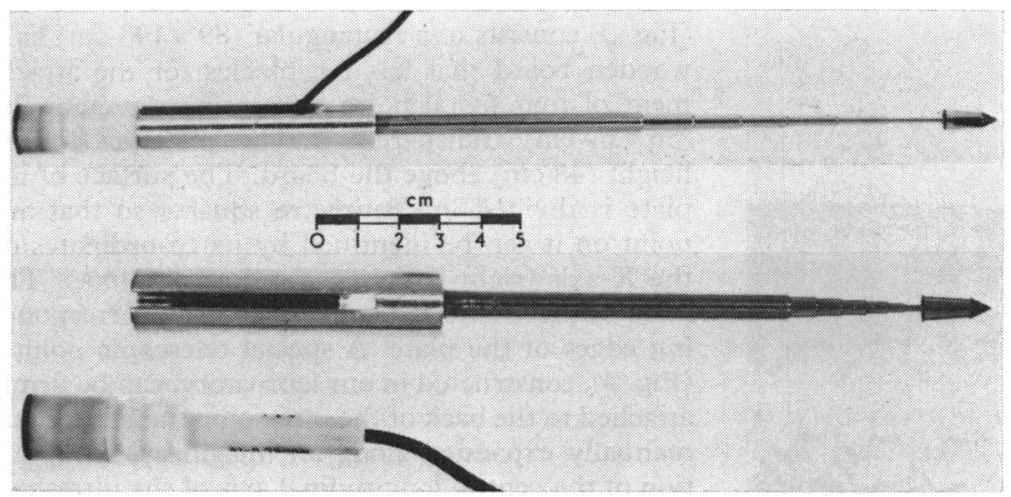

Fig. 4 The pointer before (lower) and after its attachment on the ultrasonic transducer (upper). The metric scale shown applies to the lower half of the picture only.

expands the pointer by exerting slow axial traction at its tip until the latter comes into contact with the plate at a point (B) (Fig. 5) which he marks on the plate. If this manoeuvre results in a deterioration of the resolution of the echogram, as observed on the screen of the echograph, this last step may have to be repeated until the wanted picture is restored by minor readjustments in the angle of the transducer.

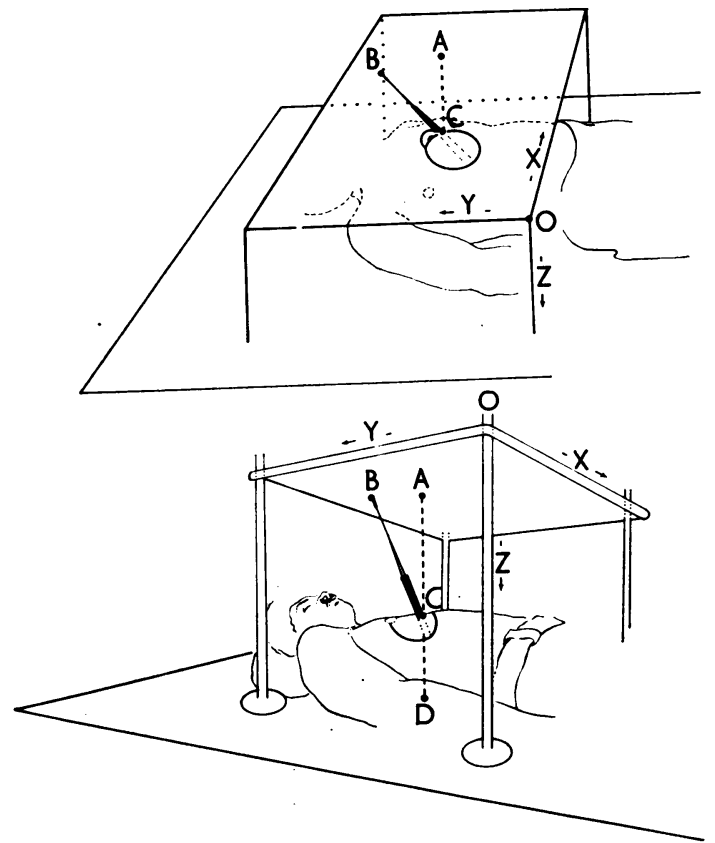

Fig. 5 Geometric representation of the reference system employed in this study as seen from above (upper) and from below (lower). The transducer is applied at point $C$ on the chest and the tip of the pointer is brought in contact with the plate at $B$. The line $A C D$ passing through point $C$ meets the plate (at $A$ ) and the board (at D), being perpendicular to both. The point of origin of the three axes $(X, Y, Z)$ is at $O$. See text for details.
The picture is then taken at the end of a passive held expiration, and the point (C) on the anterior chest wall where the transducer was applied is marked by indelible ink for use in subsequent studies. Before the restriction on movement is removed, the transducer is placed perpendicularly ${ }^{1}$ on and pressed against the inferior surface of the plate, and moved to a position (marked on the plate as point A) so that the tip of the expanded pointer coincides with point $C$ marked on the chest. Finally, the co-ordinates of points $\mathrm{A}$ and $\mathrm{B}$ on the plate are noted for future use.

In subsequent studies the reverse procedure is followed. First, the points A and B are marked on the plate using the co-ordinates noted from the first study. Then the subject is similarly placed on the board and suitably moved until the point $C$ on the chest comes on the vertical line passing from point A of the plate, as checked by use of the pointer as described above. From that moment until the end of the study the examined person is instructed to remain still in order to preserve the correspondence of points $A$ and $C$ on the same vertical line. The transducer, with the pointer on it, is then applied on the point $C$ on the chest and the pointer is expanded by an assistant until its tip comes into contact with the point $B$ on the plate and held there until the echogram is recorded after suitable adjustments of gain, depth compensation, and reject control that aim at improving the clarity of the echogram.

\section{THEORETICAL CONSIDERATIONS}

Theoretical analysis of the structure and use of the presented instrument requires the following assumptions:

(1) That the central axes of the ultrasonic beam, the transducer, and the pointer lie on the same 'The perpendicularity of the transducer and the plate is ensured by the requirement that the whole of the rim of the concave emitting surface of the transducer be kept in apposition with the inferior surface of the plate. 
straight line, termed 'ultrasonic line'.

(2) That in a relaxed person lying supine on a horizontal unyielding surface, and at the same phase of respiration and cardiac cycle, the chest with its contents represents a 'rigid body' in the sense that the distances between any and all pairs of points in it are constant (Goldstein, 1950). Two corollaries of this assumption are (a) that the position of the heart relative to the thoracic cage is constant, and (b) that if a point $(\mathrm{C})$ on the chest is perpendicularly projected on the common surface between the chest and the board at a point (D), the distance CD is constant (Fig. 5).

The following analysis is based on the principle that the position of a line relative to a 'rigid body' is completely defined if the position of each, relative to an independent reference frame, is defined.

\section{I: Definition of position of ultrasonic line}

The system composed of the board, the plate, and the connecting poles represents a reference frame $(\mathrm{X}, \mathrm{Y}, \mathrm{Z})$ in relation to which the spatial orientation of the ultrasonic line can be adequately defined and reproduced by use of the co-ordinates of any two points (B and C) on this line (Fig. 5). Point B is completely defined by its two co-ordinates $(\mathrm{X}, \mathrm{Y})$ measured on the plate, the third co-ordinate, $Z$, being zero. Point $\mathrm{C}$ is also defined for the following reasons. Since point $C$ (on the chest) and point $A$ (on the plate) lie on the same vertical line (ACD), the $\mathrm{X}$ and $\mathrm{Y}$ co-ordinates of $\mathrm{C}$ are those of $\mathrm{A}$ and can be read on the plate. The third co-ordinate of point $C$ along the $Z$ axis is the segment $A C=A D-C D$; since $\mathrm{AD}$ (the distance between board and plate) is fixed and the segment $C D$ is, for a given patient, constant (assumption 2b), it follows that their difference $(\mathrm{AC})$ is also constant and need not be measured. Therefore, knowledge of the $\mathrm{X}$ and $\mathrm{Y}$ coordinates of points $A$ and $B$ alone defines the position of the ultrasonic line relative to the reference frame and permits its reproduction in the second and subsequent studies.

\section{Definition of position of chest}

The position of a three-dimensional object relative to a reference frame is defined by the co-ordinates of any three non-collinear points of this object. In the case of the chest, definition of only one of its points (C) is not an adequate condition to guarantee reproducibility of the position of the chest relative to the same reference frame. This is because, even with the point $C$ fixed in space, the chest could still be rotated around an imaginary axis passing through point $C$ and being parallel to (1) the $X$ axis, (2) the $Y$ axis, or (3) the $Z$ axis, singly or in combination. However, the force of gravity and the presence of the board impose additional constraints limiting the degrees of freedom of movement of the chest. Thus, case 1 is obviously prevented by the presence of the board; case 2 would require determined muscular effort on behalf of the examined person to have one side of his body lifted from the board, which is not expected; and the requirement that the long axis of the body be kept parallel to that of the board prevents situation (3), unless the deviation is small enough to escape visual observation, in which case it is likely to be insignificant.

Thus, theoretically at least, the position of the chest, and (by assumption 2a) of the heart, relative to the reference frame, is reproducible. Since the position and spatial orientation of the ultrasonic line relative to the same reference frame was shown to be reproducible, it follows that the position of the ultrasonic line relative to the heart is also reproducible.

\section{Results}

A representative echogram is shown in Fig. 2. The results from group I are listed in detail in Table 1 and graphically depicted in Fig. 6. In this group, over a wide range of left ventricular end-diastolic dimension ( 35.5 to $77 \mathrm{~mm}$ ), the differences in $\mathrm{Dd}$, Ds, and $\Delta D$ between studies were statistically insignificant. Thus, comparison of studies $\mathbf{A}$ and $\mathbf{B}$ (same observer, different times) showed differences ranging from -3.5 to +3.5 (mean 0 ) $\mathrm{mm}$ for $\mathrm{Dd}$; from -2 to +2.5 (mean 0 ) $\mathrm{mm}$ for Ds; and from -4 to +3.5 (mean 0 ) $\mathrm{mm}$ for $\Delta \mathrm{D}$. Comparison between studies $B$ and $C$ (different observers, same study period) identified differences ranging from -3.5 to +3 (mean -0.5 ) for $\mathrm{Dd}$; from -3 to +2.5 (mean -0.5 ) $\mathrm{mm}$ for $\mathrm{Ds}$; and from -2.5 to +4 (mean $0) \mathrm{mm}$ for $\Delta \mathrm{D}$. Comparison between studies $\mathrm{A}$ and C (different observers, different times) disclosed differences ranging from -3 to +3 (mean 0 ) $\mathrm{mm}$ for $\mathrm{Dd}$; from -3 to +2 (mean 0 ) $\mathrm{mm}$ for $\mathrm{Ds}$; and from -3.5 to +3 (mean 0.5 ) $\mathrm{mm}$ for $\Delta \mathrm{D}$.

The results from group II are listed in detail in Table 2 and graphically depicted in Fig. 6. As in group I, the differences in Dd or Ds in this group (II) as a whole were statistically insignificant. Yet, despite the somewhat narrower range of enddiastolic left ventricular dimensions encountered in group II (40 to $65.5 \mathrm{~mm}$ ), the individual variations in $\mathrm{Dd}, \mathrm{Ds}$, and $\Delta \mathrm{D}$ observed in this group between studies and between observers were occasionally unacceptably large. Thus, in comparing studies $\mathbf{A}$ and B (same observer, different times) the differences ranged from -6 to $+10 \cdot 5$ (mean 0 ) $\mathrm{mm}$ for $\mathrm{Dd}$; from -6 to +8.5 (mean 1 ) $\mathrm{mm}$ for Ds; and from -7.5 to +7 (mean -1$) \mathrm{mm}$ for $\Delta \mathrm{D}$. When studies $\mathrm{B}$ and $\mathrm{C}$ 

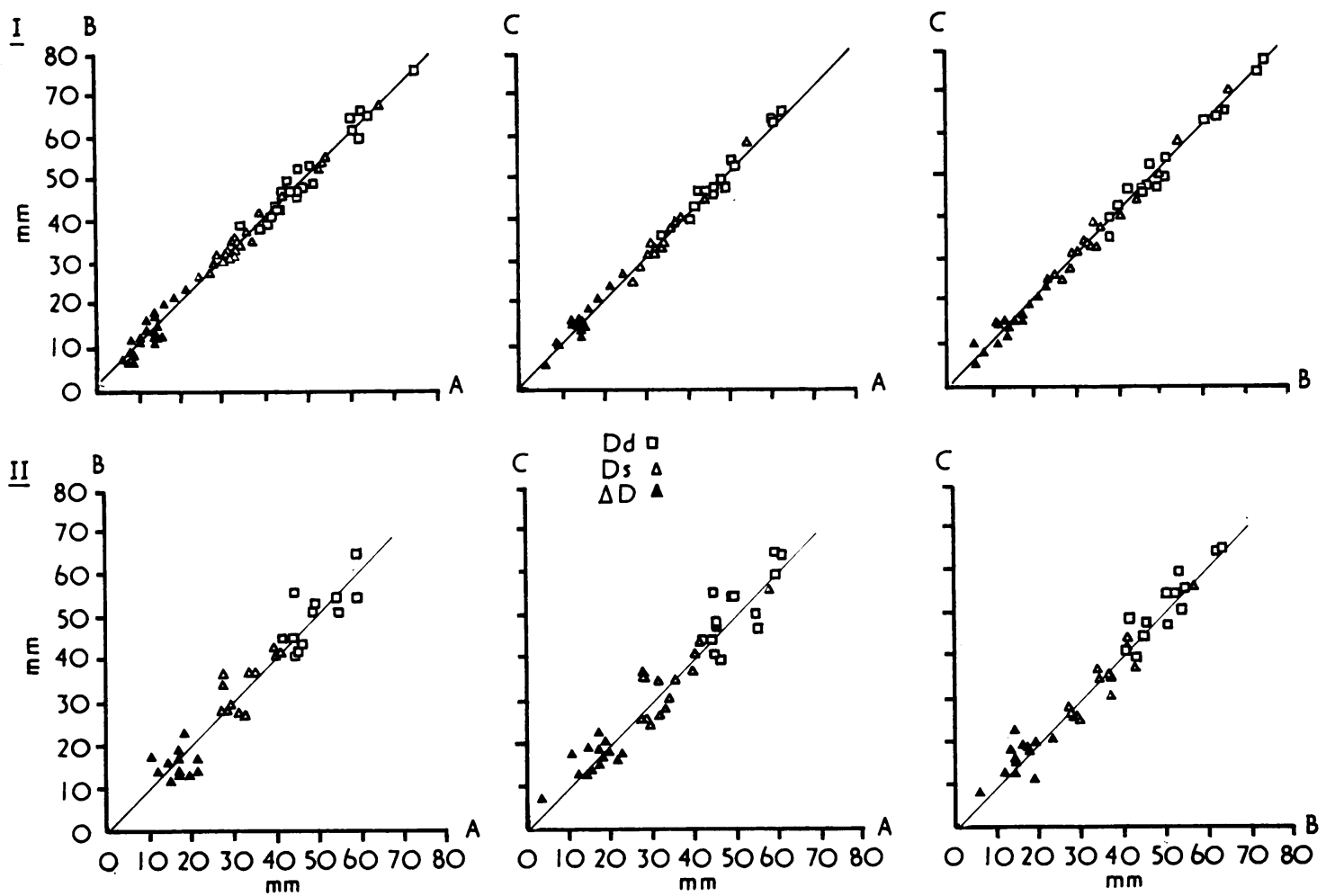

Fig. 6 Comparison of left ventricular end-diastolic dimension (Dd, open squares), end-systolic dimension (Ds, open triangles), and their difference ( $\Delta D$, closed triangles), in group I (upper) and group II (lower). between studies $A$ versus $B$ (left), $A$ versus $C$ (middle), and $B$ versus $C$ (right). The lines of identity are shown. Comparisons between studies with significant difference in heart rate (see Tables) were omitted.

were compared (different observers, same study period), the differences ranged from -3.5 to +7 (mean 1) $\mathrm{mm}$ for Dd; from -6 to +3 (mean -1$) \mathrm{mm}$ for Ds; and from -2 to +9 (mean $2^{1}$ ) $\mathrm{mm}$ for $\Delta \mathrm{D}$. Comparison between studies $\mathbf{A}$ and $\mathbf{C}$ (different observers, different times) disclosed differences ranging from -8 to +11 (mean 1.5 ) $\mathrm{mm}$ for $\mathrm{Dd}$; from -5 to +9 (mean 0 ) for Ds; and from -5 to +7.5 (mean 1.5$) \mathrm{mm}$ for $\Delta \mathrm{D}$. These data indicate that the use of the instrument is free of any systematic bias in one direction but are not adequate to document its usefulness since-except for $\Delta \mathrm{D}$ such bias was also absent in the measurements made in group II where the instrument was not employed.

In order to establish the superiority of using the instrument (group I) over the old method not using it (group II), the individual differences in $\mathrm{Dd}, \mathrm{Ds}$, and $\Delta D$ noted between studies $A, B$, and $C$ in group I were compared with those observed in group II, using the non-paired Student's $t$ test for absolute 'Statistically significant difference. differences from the mean. This test compares the degree of random variation (irrespective of direction) of individual measurements observed in one group to those obtained in the other. The results are listed in Table 3. Thus, in group II where the instrument was not used, the average differences in $\mathrm{Dd}, \mathrm{Ds}$, and $\Delta \mathrm{D}$ between studies $\mathrm{A}$ and $\mathrm{B}$ (same observer at different times) were 1.9 to 2.7 times larger $(P<0.01)$ than those found in similar studies in group I which had the benefit of the instrument. Similarly, the average differences between studies A and $C$ (different observers at different times) seen in group II were 2.1 to 3.5 times larger $(P<0.02)$ than those seen in group II. In the case of comparison between studies $B$ and $C$ (different observers at same study period) the average differences in Dd, Ds, and $\Delta \mathrm{D}$ in group II were only 1.5 to 1.7 times larger than those observed in group I, the improvement being statistically insignificant for this number of observations. These data indicate that, in comparison with the old method, the use of the instru- 
Table 3 Statistical comparison of differences in echocardiographic variables between studies $A, B$, and $C$, in two groups of subjects ( $I$ and II)

\begin{tabular}{|c|c|c|c|c|}
\hline & & \multicolumn{3}{|l|}{ Comparison } \\
\hline & & $\begin{array}{l}A \text { versus } B \\
\text { (Same observer at different } \\
\text { times) }\end{array}$ & $\begin{array}{l}A \text { versus } C \\
\text { (Different observers at different } \\
\text { times) }\end{array}$ & $\begin{array}{l}\text { B versus } C \\
\text { (Different observers at same study } \\
\text { period) }\end{array}$ \\
\hline Difference in Dd: & $\begin{array}{l}\text { Group I } \\
\text { Group II } \\
\text { P }\end{array}$ & $\begin{array}{r}1.82 \pm 0.26\left(n_{1}=22\right) \\
3.71 \pm 0.78\left(n_{2}=12\right) \\
<0.01\end{array}$ & $\begin{array}{r}1.27 \pm 0.27\left(n_{1}=13\right) \\
4.43 \pm 0.76\left(n_{2}=14\right) \\
<0.001\end{array}$ & $\begin{array}{l}1.56 \pm 0.26\left(n_{1}=16\right) \\
2.54 \pm 0.58\left(n_{2}=14\right) \\
\text { NS }\end{array}$ \\
\hline Difference in Ds: & $\begin{array}{l}\text { Group I } \\
\text { Group II }\end{array}$ & $\begin{array}{r}1.04 \pm 0.16\left(n_{1}=22\right) \\
2 \cdot 79 \pm 0.81\left(n_{2}=12\right) \\
<0.01\end{array}$ & $\begin{array}{r}1.15 \pm 0.23\left(n_{1}=13\right) \\
3.57 \pm 0.67\left(n_{2}=14\right) \\
<0.05\end{array}$ & $\begin{array}{l}1.37 \pm 0.23\left(n_{1}=16\right) \\
2 \cdot 32 \pm 0.52\left(n_{2}=14\right) \\
\text { NS }\end{array}$ \\
\hline Difference in $\Delta \mathrm{D}:$ & $\begin{array}{l}\text { Group I } \\
\text { Group II } \\
\text { P }\end{array}$ & $\begin{aligned} & 1.95 \pm 0.28\left(n_{1}=22\right) \\
& 3.75 \pm 0.67\left(n_{2}=12\right) \\
&<0.01\end{aligned}$ & $\begin{array}{r}1.58 \pm 0.26\left(n_{1}=13\right) \\
3.29 \pm 0.58\left(n_{2}=14\right) \\
<0.02\end{array}$ & $\begin{array}{l}1.69 \pm 0.26\left(n_{1}=16\right) \\
2.57 \pm 0.60\left(n_{2}=14\right) \\
\text { NS }\end{array}$ \\
\hline
\end{tabular}

$n_{1}$ and $n_{2}=$ number of subjects of group I and group II, respectively, participating in each comparison; subjects (identified in Tables 1 and 2) with significant change in heart rate between studies were excluded from respective comparison.

NS = statistically insignificant difference between group I and group II.

ment significantly improved the scatter of individual measurements of $\mathrm{Dd}, \mathrm{Ds}$, and $\Delta \mathrm{D}$ between studies carried out at different times by the same or a different observer.

\section{Discussion}

Using estimates of one left ventricular dimension obtained by echocardiography, conclusions regarding the size, output, and performance of this chamber are drawn, and important diagnostic, therapeutic, and prognostic decisions are made. In establishing the presence and quantifying the degree of either improvement or deterioration in left ventricular performance by echocardiography, reproducibility of measurements of left ventricular dimension at different times or between observers is imperative. Left ventricular echograms can be obtained from several points of the anterior chest wall and at different angulation of the transducer, but the number of different left ventricular dimensions thus obtained is greatly restricted by the requirement of simultaneously recording continuous echoes from the endocardium of both the left ventricular posterior wall and the left side of the interventricular septum at the level of the mitral valve or the chordae tendineae which must also be represented on the same echogram. In our experience and that of Popp et al. (1975), in several cases more than one echocardiographic left ventricular dimension is obtainable in duplicate studies, despite adherence to this principle. Reproducibility studies have been conducted by Pombo et al. (1971) on a group of 11 patients in whom echocardiographic left ventricular dimensions were measured by two independent observers within an interval of 1 hour to 30 days. Though differences in left ventricular dimen- sions between studies were insignificant in the group as a whole, individual variations in either enddiastolic or end-systolic left ventricular dimension reached levels comparable to those observed in our group II.

The technique of $\mathrm{M}$-mode sector scan (Feigenbaum and Chang, 1972) certainly represents a significant improvement since the proper left ventricular dimension may be selected out of a meridional crosssection of the left ventricle passing through the apex and the aortic valve. Certain difficulties are, however, associated with this technique. First, such complete sector scans are more difficult to obtain than single left ventricular echograms with a stationary transducer, even by experienced examiners. Second, continuous movement of the transducer during scanning may result in obtaining enddiastolic and end-systolic left ventricular dimensions from different points of the left ventricular wall. Third, this technique requires a strip-chart echocardiographic recorder, an expensive instrument not available in all laboratories. Fourth, $\mathrm{M}$-mode sector scans can be obtained on a patient from more than one intercostal space with significant effects on the left ventricular dimension measured from each interspace, as recently shown by Popp et al. (1975). Their concept of the 'standard interspace' defined as the one that 'permits recording of the anterior mitral leaflet while the transducer is held perpendicular to the chest wall, with only slight medial but no superior or inferior angulation'-is a positive step in the effort to standardise measurements of the echocardiographic left ventricular dimension. Use of the 'standard interspace' by these investigators resulted in a small difference (0 to 4 , mean $0.5 \mathrm{~mm}$ ) in left ventricular dimensions measured on duplicate echograms carried out during the same study 
period on 14 patients. However, data concerning the use of this method at different times and by different observers are not available.

The instrument employed in this study is inexpensive and its use prolongs the examination only for a few minutes. Its disadvantages are that (1) it can only be used with the patient in the supine position; (2) it necessitates marking the point of application of the transducer on the chest, for use in subsequent studies; and (3) it requires the help of an assistant to expand the pointer and keep its tip in contact with the plate, during the recording of the echogram. Compared with theoretical estimates of Linhart et al. (1975), these data indicate that the variability of measurements obtained using this instrument on individual patients at different times and by different observers justifies its use for follow-up studies of left ventricular performance.

The authors thank Dr. A. Calhoun Witham and Dr. Martin J. Frank, who reviewed this manuscript and Dr. Rollie J. Harp for invaluable statistical advice.

\section{References}

Cooper, R. H., O'Rourke, R. A., Karliner, J. S., Peterson, K. L., and Leopold, G. R. (1972). Comparison of ultrasound and cineangiographic measurements of the mean rate of circumferential fiber shortening in man. Circulation, 46, 914.

Feigenbaum, H., and Chang, S. (1972) Echocardiography, pp. 29-34 and 114-115. Lea and Febiger, Philadelphia.

Feigenbaum, H., Stone, J. M., Lee, D. A., Nasser, W. K., and
Chang, S. (1970). Identification of ultrasound echoes from the left ventricle by use of intracardiac injections of indocyanine green. Circulation, 41, 615.

Fortuin, N. J., Hood, W. P., Jr., and Craige, E. (1972). Evaluation of left ventricular function by echocardiography. Circulation, 46, 26.

Fortuin, N. J., Hood, W. P., Jr., Sherman, M. E., and Craige, E. (1971). Determination of left ventricular volumes by ultrasound. Circulation, 44, 575.

Goldstein, H. (1950). Classical Mechanics, pp. 93-94. AddisonWesley, Reading, Massachusetts.

Linhart, J. W., Mintz, G. S., Segal, B. L., Kawai, N., and Kotler, M. N. (1975). Left ventricular volume measurements by echocardiography: fact or fiction? American Fournal of Cardiology, 36, 114.

Paraskos, J. A., Grossman, W., Saltz, S., Dalen, J. E., and Dexter, L. (1971). A noniuvasive technique for the determination of velocity of circumferential fiber shortening in man. Circulation Research, 29, 610.

Pombo, J. F., Troy, B. L., and Russell, R. O., Jr. (1971). Left ventricular volumes and ejection fraction by echocardiography. Circulation, 43, 480.

Popp, R. L., Filly, K., Brown, O. R., and Harrison, D. C. (1975). Effect of transducer placement on echocardiographic measurements of left ventricular dimensions. American fournal of Cardiology, 35, 537.

Popp, R. L., and Harrison, D. C. (1970). Ultrasonic cardiac echography for determining stroke volume and valvular regurgitation. Circulation, 41, 493.

Popp, R. L., Wolfe, S. B., Hirata, T., and Feigenbaum, H. (1969). Estimation of right and left ventricular size by ultrasound. A study of the echoes from the interventricular septum. American fournal of Cardiology, 24, 523.

Requests for reprints to Dr. Miltiadis A. Stefadouros, Division of Cardiology, Medical College of Georgia, Augusta, Georgia 30902, U.S.A. 